\title{
Clinical results of entrance dose in vivo dosimetry for high energy photons in external beam radiotherapy using MOSFETs
}

\author{
J. P. Morton ${ }^{1,2}$, M. Bhat ${ }^{1,2}$, T. Williams ${ }^{1}$ and A. Kovendy ${ }^{3}$ \\ ${ }^{1}$ Department of Physics IT and Engineering, Adelaide Radiotherapy Centre, Adelaide, Australia \\ ${ }^{2}$ School of Chemistry and Physics. University of Adelaide, Adelaide, Australia \\ ${ }^{3}$ North Coast Cancer Institute, Coffs Harbour Health Campus, Coffs Harbour, Australia
}

\begin{abstract}
Thomson and Nielsen TN-502 RD MOSFETs were used for entrance dose in vivo dosimetry for 6 and 10 MV photons. A total of 24 patients were tested, 10 breast, 8 prostate, 5 lung and 1 head and neck. For prostates three fields were checked. For all other plans all fields were checked. An action threshold of $8 \%$ was set for any one field and $5 \%$ for all fields combined. The total number of fields tested was 56, with a mean discrepancy of $1.4 \%$ and S.D. of 2.6\%. Breasts had a mean discrepancy of $1.8 \%$ and S.D. of $2.8 \%$. Prostates had a mean discrepancy of $1.3 \%$ and S.D. of $2.9 \%$. For 3 fields combined, prostates had a mean of $1.3 \%$ and S.D. of $1.8 \%$. These results are similar to results obtained with diodes and TLDs for the same techniques.
\end{abstract}

Key words MOSFET, in vivo dosimetry, radiotherapy, photons

\section{Introduction}

Entrance dose in vivo dosimetry is a well established practice worldwide, with guidelines written by both $\mathrm{ESTRO}^{1}$ and the $\mathrm{AAPM}^{2}$ on the implementation of diode entrance dose in vivo dosimetry. It has shown its usefulness as a means of detecting errors that would have passed through the treatment chain unnoticed and affected patient outcome $^{3-4}$. Even with Record and Verify (R\&V) systems in place errors can be made and left undetected ${ }^{4}$.

Studies have been carried out with TLD's and diodes, giving typical mean discrepancies and standard deviations for different treatments $\mathrm{s}^{3,5-16}$.

MOSFETs have also been evaluated as an in vivo dosimeter, and have been found to be suitable as an in vivo dosimete ${ }^{17-19}$. Comparisons between diodes and MOSFETs have been made with a build up cap showing that the total uncertainty with diodes is similar to that of MOSFETs for entrance dose in vivo dosimetry measurements ${ }^{20}$. The addition of a build up cap with high energy photons is

Corresponding author: Jason Morton, Adelaide Radiotherapy

Centre, 352 South Terrace, Adelaide, SA, 5000, Australia

Tel: +61 88179 5535, Fax: +6188276 7822

Email:jmorton@adradcentre.com.au

Received: 28 May 2007; Accepted: 5 November 2007

Copyright (C) 2007 ACPSEM essential for entrance dose in vivo dosimetry as low energy contamination at the surface needs to be removed and electronic equilibrium established for reliable entrance dose in vivo dosimetry measurements $\mathrm{s}^{1,2,20}$.

MOSFETs have been shown to be suitable as an entrance dose in vivo dosimeter in Total Body Irradiation $(\mathrm{TBI})^{21}$. They have also been used for in vivo dosimetry in inter operative radiotherapy ${ }^{22}$, as well as a surgically implantable in vivo dosimeter ${ }^{23-25}$.

To date no studies have been presented showing results of entrance dose in vivo dosimetry for 3D conformal radiotherapy (3DCRT) using MOSFETs. Studies have, however been done on 10 MV IMRT prostates with a brass build up cap $^{26}$. IMRT is different in its application to 3DCRT in that in 3DCRT accessories such as wedges and blocks are often used to "conform" the beam to the shape desired. 3DCRT normally employs MLC leaves and/or blocks to define the field shape, and, where necessary wedges (either hard or dynamically created) to modulate the dose to the tumour volume. The presence of these accessories adds extra correction factors and uncertainties to entrance dose in-vivo dosimetry that would not be present in an IMRT plan ${ }^{20,26}$. In IMRT the use of blocks and wedges is removed. Dose modulation is achieved by delivering a dose distribution using MLC leaves using either step and shoot or dynamic delivery, or by introducing a compensator to the beam. Due to the different nature of beam delivery there is a direct relationship between the central axis dose and the dose to another point on a plan in a 3DCRT plan when a wedge is used. This is not true for 
IMRT. In IMRT cases the relationship is determined by dose optimization algorithms. This means that an entrance dose measurement check for a 3DCRT field will give an estimate of the error for the whole field. In the case of IMRT a dose fluence check is performed on a patient by patient basis.

This paper covers the clinical use of MOSFETs for entrance dose in vivo dosimetry for $6 \mathrm{MV}$ and $10 \mathrm{MV}$ photons for 3DCRT plans.

\section{Materials and methods}

\section{MOSFET calibration and characteristics}

Thomson and Nielsen TN-502 RD standard sensitivity isotropic MOSFETs were used. A single MOSFET was placed in a hemispherical aluminium build up cap. The Xray beam energies were 6 and $10 \mathrm{MV}$ on a Siemens Primus, and $6 \mathrm{MV}$ on a Siemens Mevatron. The bias supply used was the Thomson and Nielsen TN-RD-22 bias supply with the bias set to normal.

Prior to implementation of MOSFETs for in vivo dosimetry they were investigated thoroughly for angular, field size, and SSD (dose rate) dependence, constancy, dose-reproducibility, and linearity without a build up cap. Angular, field size, SSD, wedge and tray correction factors were also studied in a build up cap. With a build up cap correction factors were necessary for field size, wedge and trays $^{27}$. These correction factors were included in entrance dose calculations.

Calibration was performed regularly against an ion chamber traceable to a primary standards laboratory (ARPANSA). The MOSFET calibration mV/Gy was constant, with a standard deviation of $2.6 \%$ over a period of 6 months $^{27}$.

\section{Phantom study prior to clinical implementation}

To suitably implement IVD in a clinical setting uncertainties involved in the measurement should be studied beforehand. An action threshold is generally given above which the measurement is either repeated and/or the setup investigated ${ }^{1}$.

The action threshold should not be chosen arbitrarily as choosing the wrong action threshold can lead to time wasted on investigations into errors which do not exist ${ }^{15}$. This in turn leads to lack of confidence in the new techniques being offered. Action levels are based on 2 standard deviations from the mean measurement ${ }^{1,15}$. For a centre with calibrated diodes and a program in place to implement in vivo dosimetry regularly this is about 5 to $8 \%{ }^{1}$.

Very few centres have an average standard deviation of less than $2.9 \%$ ( 1 S.D.) from the expected mean of $1.00^{1}$, while the standard deviation and mean of results varies from centre to centre, as well as from one treatment to the next ${ }^{1}$. Typically the error will be distributed normally around a mean. The standard deviation of this error can then be used to determine the action level that a department needs to check errors in setup or parameters ${ }^{1}$.
Prior to patient measurements plans were created for a lung/thorax phantom. This phantom consisted of a central bony structure like a spine, with lung density material for lungs and water equivalent material for the rest. The plans created were designed to test whether entrance dose measurements would cope with different scatter and setup conditions. The dose calculated with Radcalc was also compared to an independently made spreadsheet which calculated the dose to the target based on the relationship given in Equation 1. These doses were also compared to the calculated dose in the 3D planning system (Pinnacle 3D). The percentage difference was taken as the difference to Pinnacle $3 \mathrm{D}$ at the isocentre with the spreadsheet and the difference to the expected $D_{\max }$ dose for Radcalc.

$D_{\text {iso }}=\frac{\operatorname{TMR}(A, z) *\left(100-z+d_{\text {max }}\right)^{2}(100-z)^{2}}{(100)^{2} * B_{A}^{\prime} *\left(100-z_{\text {eff }}\right)^{2}} * D_{\text {ent }}$

where $A$ is the field size, $z$ is the physical depth, $Z_{\text {eff }}$ the effective depth, $B^{\prime}{ }_{A}$ the ratio of the backscatters for the field size at the isocentre and the entrance $\left(D_{\max }\right)$ (This was taken as 1.00$), D_{\text {iso }}$ the isocentric dose and, $D_{\text {ent }}$ the entrance dose.

A total of 5 plans were created with fields passing through lung material and containing normal to high obliquity. Each plan consisted of 3 fields. A sample plan is included in Figure 1. These plans included hard wedges and were delivered for both $6 \mathrm{MV}$ and $10 \mathrm{MV}$. Dose points were placed in tissue equivalent material at the isocentre. Entrance dose measurements were compared between the spreadsheet and Radcalc to ensure that Radcalc gave accurate results for entrance dose measurements. The means and standard deviations of all measurements were taken. From these means and standard deviations action threshold levels were established.

\section{Clinical setup and action thresholds}

Radiation therapists were trained in an informal session on the placement of the MOSFET on the patient. The SSD to the skin surface was taken as the SSD for the MOSFET.

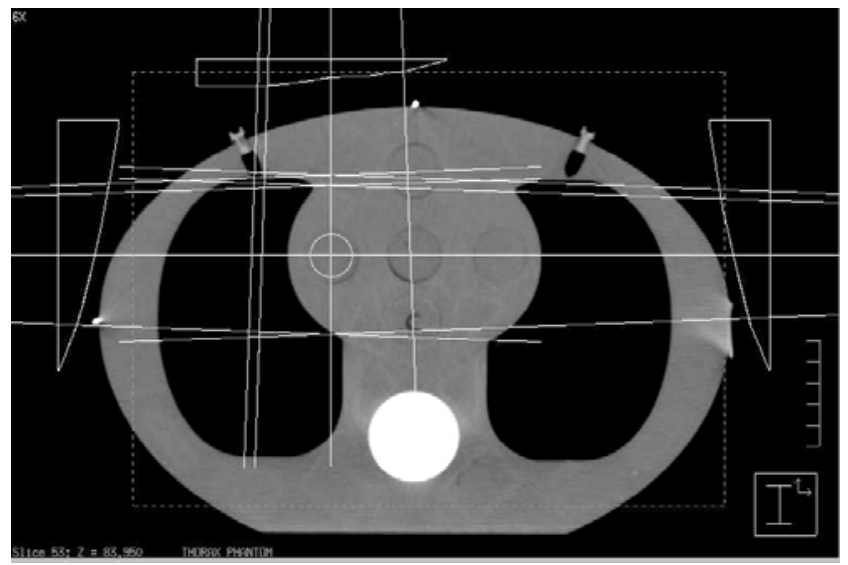

Figure 1. Sample lung/thorax plan for testing entrance dose measurements. 
Table 1. Treatment summary.

\begin{tabular}{lcc}
\hline Treatment & Number of patients & Number of fields \\
\hline Breast & 10 & 20 \\
Prostate/pelvis & 9 & 27 \\
Lung/head and neck & 3 & 6 \\
Head and neck & 1 & 2 \\
Total & 23 & 55 \\
\hline
\end{tabular}

For fields passing through the couch, (eg. PA fields) the build up cap was placed on the couch, and the SSD to the couch taken. The build up cap was placed on the central axis whenever it was possible. For dose estimates from MOSFET measurements, Radcalc, a commercially available secondary MU checker was used. The Radcalc “diode measurement" facility was modified for MOSFET entrance dose measurements. Correction factors were made in a similar way to diodes and the entrance dose calibration factor was added from the MOSFETs ${ }^{27}$.

For prostates three measurements were made as checking all fields with a seven field prostate treatment would take too long. The three fields checked were the AP, left and right lateral fields. These three fields give an indication of the patient positioning as a displacement or incorrect patient setup would result in one of these readings being out. At these orientations the beam is also normal to the surface of the patient therefore angular dependence and would be less significant. It is also easier to place the MOSFET at these orientations. For all other treatments all fields were tested.

An action threshold of $8 \%$ was set for any single measurement based on phantom measurements in a lung/thorax phantom. For all fields an action threshold of $5 \%$ was set. If results were outside the action threshold they were repeated during the next patient treatment and the source of the error investigated.

A total of 23 patients were tested. Table 1 contains a tabulation of treatment delivery types.

\section{Uncertainty}

As MOSFET uncertainty decreases at a rate greater than $\frac{1}{\sqrt{D}}$, where $\mathrm{D}$ is the dose received by the MOSFET, a power relationship for measurement uncertainty was adopted based on standard deviations of linearity measurements over the range 17.2 to $400 \mathrm{cGy}^{27}$. The standard deviation was of a single measurement was taken as

$\sigma=\frac{1.2836 x^{-0.6485}}{3}$

where $\mathrm{x}$ is the dose in $\mathrm{cGy}^{27}$.

For the purposes of this paper a MOSFET measurement uncertainty is called uncertainty, a systematic error or treatment error is called an error, and the difference between the entrance dose reading on a patient and the expected reading is called a discrepancy.

The absolute discrepancy was graphed as a change in MOSFET standard deviation would be noticed on a graph of absolute discrepancy by a decrease in the spread of results.

\section{Results}

\section{Lung/thorax phantom}

Of the total of 5 plans (15 fields) the average was $2.0 \%$ and the standard deviation $3.1 \%$. The maximum difference was $6.9 \%$. This was repeated as it was too high. On repeat the result was $-1.0 \%$. Radcalc and the spreadsheet presented similar results to Pinnacle (Table 2). As the standard deviation was $3.1 \%$ two standard deviations would be $6.2 \%$. The average typical standard deviation of diodes for patient measurements is about $2.8 \%$. As diodes have a high precision this $2.8 \%$ was added in quadrature to the $3.1 \%$ from lung/thorax phantom measurements to get a representative value for expected dose to the patient. Taking 2 times the combined uncertainty for these two measurements gives approximately $8 \%$. This was taken as the maximum error for any 1 field before investigation. Because multiple fields would have a lower uncertainty than any one field a tolerance of $5 \%$ was set for all fields measured for a treatment. These tolerances are also similar to those of other institutions ${ }^{1}$.

\section{Breasts}

Breast results were normally distributed around a mean, with an average discrepancy of $1.8 \%$ and a standard deviation of $2.8 \%$ (Figure 2). These results are similar to those of other institutions using diodes, and is not worse than institutions implementing large scale diode in vivo dosimetry $(\mathrm{SD}=3.1$ and $3.5 \%$ for Leuven and Milan respectively ${ }^{1}$ ).

\section{Prostates and pelvis}

Prostate and Pelvis measurements were grouped together. These treatments had results distributed around a mean, with an average discrepancy of $1.3 \%$ and a standard deviation of $2.9 \%$. This is similar to results found in other institutions (S.D. $2.7 \%$ and $3.0 \%{ }^{1}$ ), but worse than some diode studies might suggest (S.D. $1.5 \%{ }^{5}$ and $1.2 \%{ }^{8}$ ). Absolute measurement discrepancy did not decrease 
Table 2. Lung/thorax phantom results.

\begin{tabular}{lrcc}
\hline Plan & Wedge & TMR spreadsheet \% difference & Radcalc \% difference \\
\hline dp1 6MV & 0 & $-1.3 \%$ & $-1.0 \%$ \\
dp1 6MV & 60 & $-4.3 \%$ & $-4.7 \%$ \\
dp1 6MV & 45 & $5.3 \%$ & $5.0 \%$ \\
dp2 6MV & 15 & $0.4 \%$ & $0.4 \%$ \\
dp2 6MV & 30 & $3.0 \%$ & $3.3 \%$ \\
dp2 6MV & 15 & $4.0 \%$ & $4.0 \%$ \\
dp3 6MV & 0 & $3.5 \%$ & $3.2 \%$ \\
dp3 6MV & 15 & $5.9 \%$ & $5.9 \%$ \\
dp3 6MV & 30 & $-0.7 \%$ & $-0.7 \%$ \\
dp3 6MV & 0 & $3.5 \%$ & $3.7 \%$ \\
dp3 6MV & 15 & $-0.2 \%$ & $0.5 \%$ \\
dp3 6MV & 30 & $5.9 \%$ & $6.9 \%$ \\
dp2 10MV & 15 & $-1.3 \%$ & $-2.2 \%$ \\
dp2 10MV & 30 & $5.3 \%$ & $5.0 \%$ \\
dp2 10MV & 30 & $1.5 \%$ & $-0.4 \%$ \\
dp3 6MV (repeat) & 30 & $-2.0 \%$ & $-1.0 \%$ \\
Mean Discrepancy & & $1.8 \%$ & $1.7 \%$ \\
S.D. & & $3.2 \%$ & $3.3 \%$ \\
\hline
\end{tabular}

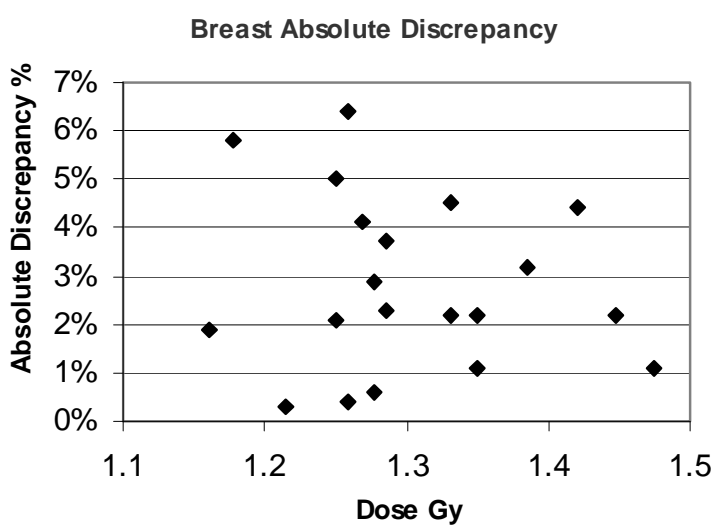

Figure 2. Breast measurements.

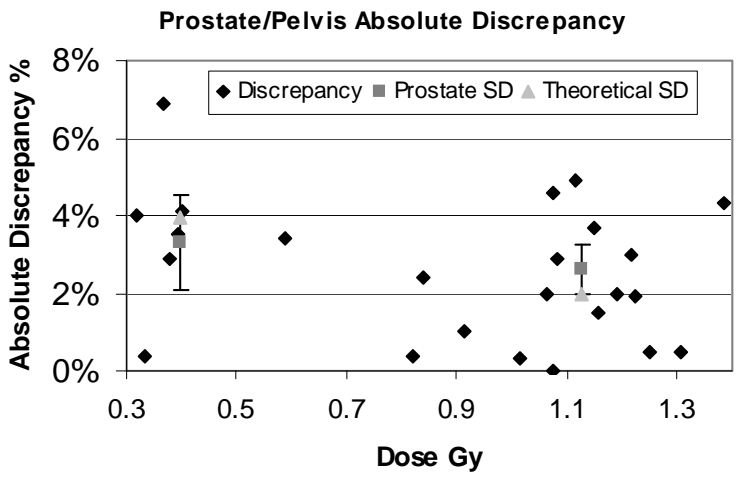

Figure 3. Prostate and pelvis measurements. significantly with an increase in dose $(r=-0.269, \mathrm{P}=0.225)$ (Figure 3, Table 3). This is an important factor as the uncertainty of a MOSFET measurement is larger at small doses. It would therefore not be unreasonable to expect a fall in the standard deviation and average absolute discrepancy with an increase in dose. If all 3 fields are considered per treatment the mean is $1.3 \%$, and standard deviation $1.8 \%$. This is comparable to the results mentioned earlier $^{5,8}$.

\section{All results}

All the results were distributed around a mean, with a mean discrepancy of 1.3\% and a standard deviation of 2.6\% (Figure 4 and Figure 5). The results were slightly negatively skewed with a skewness of $-0.39 \pm 0.33$. The distribution of results was normal, with a kurtosis of $0.34 \pm$ 0.67 . The average entrance dose delivered per field was 1.17 Gy. The standard deviation of all measurements was $2.6 \%$, slightly larger than the expected standard deviation of the MOSFET at that dose. Discrepancy means and standard deviations for patient measurements for diodes are similar to MOSFETs, even though the precision of a diode measurement is much greater than a MOSFET measurement of the same dose. One can therefore conclude that the uncertainties associated with patient setup and treatment planning are a limiting factor for entrance dose in vivo dosimetry, and that the MOSFET uncertainty, being of the same order of magnitude (as a percentage), does not significantly increase the uncertainty associated with a measurement. 
Table 3. Prostate/pelvis results.

\begin{tabular}{ccccc}
\hline Prostate SD's & Average dose & S.D. & Theoretical SD & Standard error \\
\hline Low dose & 0.40 & $3.3 \%$ & $3.9 \%$ & $1.2 \%$ \\
High dose & 1.13 & $2.6 \%$ & $2.0 \%$ & $0.6 \%$ \\
\hline
\end{tabular}

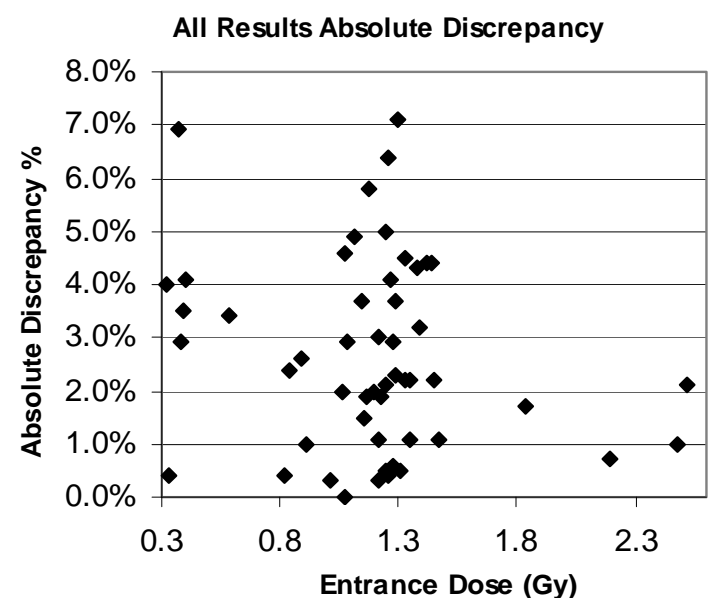

Figure 4. All measurements.

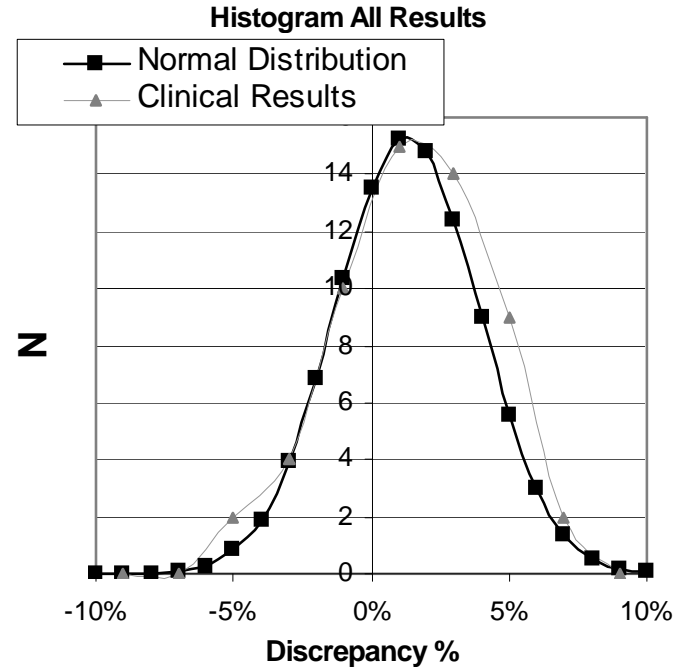

Figure 5. Histogram of results for all measurements.

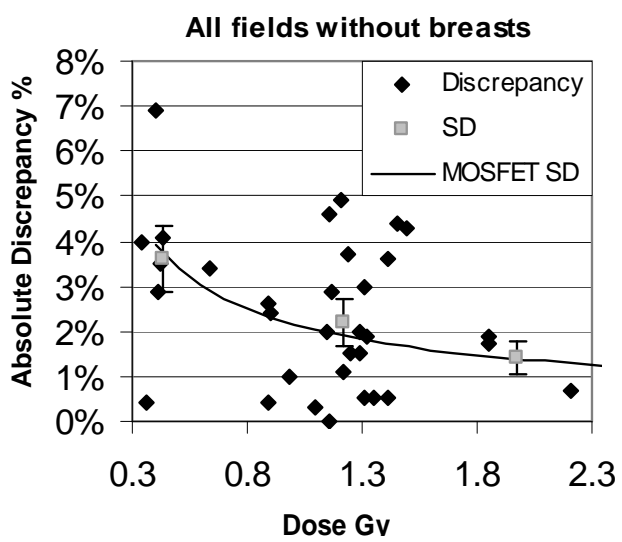

Figure 6. Discrepancy, all treatments excluding breast results. Line represents theoretical MOSFET S.D. based on power law.

\section{All results excluding breast results}

Due to the increased discrepancy associated with breast treatments some institutions look at all treatments without breast treatments included ${ }^{1}$. When all treatments except breast treatments are considered with the MOSFET measurements, the dose-discrepancy relationship shows an increase in the standard deviation with a decrease in dose (Figure 6). This is similar to the standard deviation of the MOSFET. If the MOSFET standard deviation of $\sigma=\frac{1.2836 x^{-0.6485}}{3}$ is plotted against the results the graph shows that there is a good fit between the theoretical standard deviation and the mean absolute discrepancy (Figure 6). The uncertainty in the standard deviation was taken as the standard error. If the results are broken into three groups (0.3-0.6 Gy, 0.8-1.4 Gy, 1.7-1.8 Gy) the standard deviations of the means fall along the theoretical standard deviation (Figure 6). This shows that the dose measured with the MOSFET is a factor affecting the accuracy of the entrance dose measurement for low dose measurements. The uncertainty of a measurement can be reduced by increasing the bias voltage across the MOSFET, but as the means and standard deviations for the treatments as a whole are similar to other institutions (Table 4) there is little practical advantage from increasing the bias voltage and reducing the life expectancy of the MOSFET with the exception of prostates and pelvises.

\section{Typical results for different techniques}

Results from entrance dose in vivo dosimetry tend to vary from one centre to the next, but large studies from Europe give a good indication of which results to expect.

The results depend on the field type and anatomical position. Typically breast and head and neck treatments give poor results ${ }^{2,3}$.

\section{Discussion}

Only one measurement needed to be re-measured. It was for a tangential breast and the error was tracked down to an incorrect MOSFET reading. As the reading was significantly different to the expected reading and SSD and MU's were within tolerance and would not have created such a large dose the reading was repeated during the next treatment. It was not included in these results. When the measurement was repeated the reading was within tolerance ( $8 \%$ one field, $5 \% 2$ fields combined). No other

measurements needed to be re-measured. For all plans the total combined discrepancy of all fields was within $5 \%$ of the prescribed dose.

The increase in the standard deviation of Prostate 
Table 4. Institution means and Standard Deviations for external beam radiotherapy IVD.

\begin{tabular}{|c|c|c|c|}
\hline Paper/book & Technique & Mean & $\sigma$ \\
\hline $\begin{array}{l}\text { Quality assurance by systematic in vivo dosimetry: results } \\
\text { on a large cohort of patients, Fiorino C et. al } 2000^{3}\end{array}$ & $\begin{array}{l}\text { All } \\
\text { Tangential breast } \\
\text { Vertebra } \\
\text { Brain }\end{array}$ & $\begin{array}{l}0.3 \% \\
1.0 \% \\
1.0 \% \\
-0.7 \%\end{array}$ & $\begin{array}{l}3.0 \% \\
3-4 \% \\
2.1 \% \\
2.6 \%\end{array}$ \\
\hline $\begin{array}{l}\text { Implementation of an in vivo diode dosimetry program } \\
\text { and changes in diode characteristics over a 4-year clinical } \\
\text { history, Jursinic, } 2001^{9}\end{array}$ & All & $0.5 \%$ & $1.5 \%$ \\
\hline $\begin{array}{l}\text { Accurate in vivo dosimetry of a randomized trial of } \\
\text { prostate cancer irradiation, Meijer et al } 2001^{10}\end{array}$ & Prostate & $0.9 \%$ & $1.2 \%$ \\
\hline ESTRO booklet 5, ESTRO, (Huyskens et al. 2001) ${ }^{1}$ & $\begin{array}{l}\text { All excluding breast } \\
\text { Breast mastectomy } \\
\text { Breast lumpectomy }\end{array}$ & $\begin{array}{l}0.3 \% \\
3.5 \% \\
3.1 \%\end{array}$ & $\begin{array}{l}2.7 \% \\
3.1 \% \\
4.7 \%\end{array}$ \\
\hline ESTRO booklet 5, ESTRO, (Huyskens et al. 2001) ${ }^{1}$ & $\begin{array}{l}\text { All } \\
\text { Breast } \\
\text { Brain } \\
\text { Neck } \\
\text { Pelvis }\end{array}$ & $\begin{array}{l}0.2 \% \\
0.3 \% \\
-1.0 \% \\
1.1 \% \\
0.5 \%\end{array}$ & $\begin{array}{l}3.1 \% \\
3.5 \% \\
2.8 \% \\
2.8 \% \\
3.0 \%\end{array}$ \\
\hline $\begin{array}{l}\text { Tumour dose estimation using automated TLD } \\
\text { techniques, Ferguson et al } 1998^{11}\end{array}$ & $\begin{array}{l}\text { All } \\
\text { Pelvis } \\
\text { Breast }\end{array}$ & $\begin{array}{l}-0.15 \% \\
-0.8 \% \\
0.3 \%\end{array}$ & $\begin{array}{l}3.0 \% \\
2.8 \% \\
2.9 \%\end{array}$ \\
\hline $\begin{array}{l}\text { Entrance and exit dose measurements with } \\
\text { semiconductors and thermoluminescent dosimeters: a } \\
\text { comparison of methods and in vivo results. Lancol et al } \\
1996^{6}\end{array}$ & $\begin{array}{l}\text { All (diodes) } \\
\text { All (TLDs) }\end{array}$ & $\begin{array}{l}1.0 \% \\
1.3 \%\end{array}$ & $\begin{array}{l}2.8 \% \\
4.1 \%\end{array}$ \\
\hline $\begin{array}{l}\text { Feasible measurement errors when undertaking in vivo } \\
\text { dosimetry during external beam radiotherapy of the } \\
\text { breast, Herbert C et al } 2003^{12}\end{array}$ & Tangential Breast & $4.3 \%$ & $4.0 \%$ \\
\hline $\begin{array}{l}\text { Quality assurance in radiation oncology. A study of } \\
\text { feasibility and impact on action levels of an in vivo } \\
\text { dosimetry program during breast cancer irradiation, Cozzi } \\
\text { and Cozzi, } 1998^{13}\end{array}$ & $\begin{array}{l}\text { Breast (corrections) } \\
\text { Breast (no } \\
\text { corrections) }\end{array}$ & $\begin{array}{l}-1.9 \% \\
-1.2 \%\end{array}$ & $\begin{array}{l}2.4 \% \\
2.7 \%\end{array}$ \\
\hline $\begin{array}{l}\text { In vivo dosimetry during conformal radiotherapy. } \\
\text { Requirements for and Findings of a routine procedure, } \\
\text { Lanson et al.1999 }\end{array}$ & $\begin{array}{l}\text { Prostate } \\
\text { Parotid } \\
\text { All }\end{array}$ & $\begin{array}{l}1.2 \% \\
1.3 \% \\
-1.3 \%\end{array}$ & $\begin{array}{l}1.5 \% \\
2.0 \% \\
4 \%\end{array}$ \\
\hline $\begin{array}{l}\text { The implementation of in vivo dosimetry in a small } \\
\text { radiotherapy department, Voordeckers } \mathrm{M} \text { et al.1998 }\end{array}$ & & & \\
\hline $\begin{array}{l}\text { Importance of in vivo dosimetry as part of a quality } \\
\text { assurance program in tangential breast treatments, } \\
\text { Leunens G et al. } 1993^{15}\end{array}$ & Breasts & $1.3 \%$ & $3.4 \%$ \\
\hline $\begin{array}{l}\text { Selective in vivo dosimetry in radiotherapy using P-type } \\
\text { semiconductor diodes: a reliable quality assurance } \\
\text { procedure. Howlett S et al } 1999^{16}\end{array}$ & $\begin{array}{l}\text { All Results } \\
\text { Breasts } \\
\text { Prostates }\end{array}$ & $\begin{array}{l}0.5 \% \\
0.5 \% \\
0.1 \%\end{array}$ & $\begin{array}{l}2.2 \% \\
2.3 \% \\
1.7 \%\end{array}$ \\
\hline MOSFETs & $\begin{array}{l}\text { All Results } \\
\text { Breast } \\
\text { Prostate/Pelvis }\end{array}$ & $\begin{array}{l}1.3 \% \\
1.8 \% \\
1.3 \%\end{array}$ & $\begin{array}{l}2.6 \% \\
2.8 \% \\
2.9 \%\end{array}$ \\
\hline
\end{tabular}


measurements could be exacerbated by entrance dose measurements of low dose. These treatments typically had larger standard deviations than diode studies for the same techniques. The expected standard deviation of a low dose measurement with a MOSFET is larger than the standard deviation for a higher dose measurement. Increasing the bias voltage will decrease the standard deviation at lower doses. This could decrease the standard deviation of in vivo measurements, but has not been included in this study.

For IMRT prostate treatments using a high sensitivity bias setting the standard deviation of measurements is $3.3 \%$, and no trend is observed with increasing dose ${ }^{26}$. As prostate measurements had a standard deviation of $2.9 \%$, and that large scale studies with diodes have reported a standard deviation of $2.7 \%{ }^{1}$, and no trend was observed, increasing the bias to high sensitivity will not, based on these results, and bearing in mind that IMRT is a very different treatment modality to 3DCRT, reduce the standard deviation of entrance dose results.

\section{Conclusion}

Thomson and Nielsen TN-502 RD standard sensitivity isotropic MOSFETs can be used clinically as entrance dose in vivo dosimeters when used with an appropriate build up cap. Results are similar to that of diodes and TLD's, with a mean discrepancy of $1.3 \% \pm 2.6 \%$ for all results. For all fields except breast treatments the standard deviation of measurements from the expected value increased with decreasing dose, showing that for doses less than 0.5 Gy to the surface the loss of MOSFET reading precision becomes an issue. This issue might be resolved by increasing the sensitivity of the bias box for the MOSFETs, but has not been studied for 3DCRT yet.

\section{References}

1. Huyskens, D.P., Bogaerts, R., Verstraete, J., Lööf, M., Nyström, H., Fiorino, C., Broggi, S., Jornet, N., Ribas, M. and Thwaites, D.I., 'Practical guidelines for the implementation of in vivo dosimetry with diodes in external radiotherapy with photon beams (entrance dose)', First edition ESTRO , ISBN 90-804532-3, 2001.

2. American Association of Physicists in Medicine, 'Diode in vivo Dosimetry for Patients Receiving External Beam Radiation Therapy', AAPM Report 87, Medical Physics Publishing, 2005.

3. Fiorino, C., Corletto, D., Mangili, P., Broggi, S., Bonini, A., Cattaneo, G.M., Parisi, R., Rosso, A., Signorotto, P., Villa, E. and Calandrino, R., 'Quality assurance by systematic in vivo dosimetry: results on a large cohort of patients.', Radiother Oncol. 56(1):85-95, 2000.

4. Klein, E.E., Drzymala, R.E., Purdy, J.A. and Michalski, J., 'Errors in radiation oncology: a study in pathways and dosimetric impact.' J Appl Clin Med Phys. 6(3):81-94, 2005.

5. Lanson, J.H., Essers, M., Meijer, G.J., Minken, A.W.H., Uiterwaal, G.J. and Mijnheer, B.J., 'In vivo dosimetry during conformal radiotherapy. Requirements for and Findings of a routine procedure', Radiother. and Oncol 52 51-59, 1999.
6. Loncol, T., Greffe, J.L., Vynckier, S. and Scalliet, P., 'Entrance and exit dose measurements with semiconductors and thermoluminescent dosemeters: a comparison of methods and in vivo results.', Radiother. Oncol. 41(2):179-87., 1996.

7. Voordeckers, M., Goossens, H., Rutten, J. andVan den Bogaert, W., 'The implementation of in vivo dosimetry in a small radiotherapy department', Radiother. Oncol. 47, p4548, 1998.

8. Meijer, G.J., Minken, A.W., van Ingen, K.M., Smulders, B., Uiterwaal, H. and Mijnheer, B.J., 'Accurate in vivo dosimetry of a randomized trial of prostate cancer irradiation.', Int $\mathrm{J}$ Radiat Oncol Biol Phys. 49(5):1409-18, 2001.

9. Jursinic, P.A., 'Implementation of an in vivo diode dosimetry program and changes in diodecharacteristics over a 4-year clinical history', Med Phys. 28(8):1718-26, 2001.

10. Meijer, G.J., Minken, A.W., van Ingen, K.M., Smulders, B., Uiterwaal, H. and Mijnheer, B.J. 'Accurate in vivo dosimetry of a randomized trial of prostate cancer irradiation.' Int $\mathrm{J}$ Radiat Oncol Biol Phys.49(5):1409, 2001.

11. Ferguson, H.M., Lambert, G.D., Gustard, D. and Harrison, R.M., 'Tumour dose estimation using automated TLD techniques.' Acta Oncol. 37(5):479-84, 1998.

12. Herbert, C.E., Ebert, M.A. and Joseph, D.J., 'Feasible measurement errors when undertaking in vivo dosimetry during external beam radiotherapy of the breast.', Medical Dosimetry, 28(1):45-8, 2003.

13. Cozzi, L. and Fogliata-Cozzi, A., 'Quality assurance in radiation oncology. A study of feasibility and impact on action levels of an in vivo dosimetry program during breast cancer irradiation.', Radiother Oncol., 47(1):29-36, 1998.

14. Lanson, J.H., Essers, M., Meijer, G.J., Minken, A.W., Uiterwaal, G.J. and Mijnheer, B.J., 'In vivo dosimetry during conformal radiotherapy: requirements for and findings of a routine procedure.' Radiother Oncol.52(1):51-9, 1999.

15. Leunens, G., Van Dam, J., Dutreix, A. and Van der Schueren, E., 'Importance of in vivo dosimetry as part of a quality assurance program in tangential breast treatments', Int J Radiat Oncol Biol Phys.28(1):285-96., 1994.

16. Howlett, S., Duggan, L., Bazley, S. and Kron, T., 'Selective in vivo dosimetry in radiotherapy using P-type semiconductor diodes: a reliable quality assurance procedure.', Med Dosim., 24(1):53-6, 1999.

17. Ramaseshan, R., Kohli, K.S., Zhang, T.J., Lam, T., Norlinger, B., Hallil, A. and Islam, M., 'Performance characteristics of a microMOSFET as an in vivo dosimeter in radiation therapy.', Phys Med Biol. 49(17):4031-48, 2004.

18. Halvorsen, P.H., 'Dosimetric evaluation of a new design MOSFET in vivo dosimeter', Med Phys. 32(1):110-7, 2005.

19. Soubra, M., Cygler, J. and Mackay, G., 'Evaluation of a dual bias dual metal oxide-Si semiconductor field effect transistor detector as radiation dosimeter.', Med Phys. 21(4):567-72, 1994.

20. Jornet, N., Carrasco, P., Jurado, D., Ruiz, A., Eudaldo, T. and Ribas, M., 'Comparison study of MOSFET detectors and diodes for entrance in vivo dosimetry in $18 \mathrm{MV}$ x-ray beams.', Med Phys. 31(9):2534-42, 2004.

21. Best, S., Ralston, A. and Suchowerska, N. 'Clinical application of the OneDose Patient Dosimetry System for total body irradiation.' Phys Med Biol. 21;50(24):5909-19, 2006.

22. Ciocca, M., Piazzi, V., Lazzari, R., Vavassori, A., Luini, A., Veronesi, P., Galimberti, V., Intra, M., Guido, A., Tosi, G., Veronesi, U. and Orecchia, R., 'Real-time in vivo dosimetry using micro-MOSFET detectors during intraoperative electron beam radiation therapy in early-stage breast cancer.' Radiother Oncol. 78(2):213-6, 2006. 
23. Black, R.D., Scarantino, C.W., Mann, G.G., Anscher, M.S. Ornitz, R.D. and Nelms, B.E., 'An analysis of an implantable dosimeter system for external beam therapy.', Int J Radiat Oncol Biol Phys. 63(1):290-300, 2005.

24. Scarantino, C.W., Rini, C.J., Aquino, M., Carrea, T.B., Ornitz, R.D., Anscher, M.S. and Black, R.D., 'Initial clinical results of an in vivo dosimeter during external beam radiation therapy.' Int J Radiat Oncol Biol Phys.62(2):606-13, 2005.

25. Scarantino, C.W., Ruslander, D.M., Rini, C.J., Mann, G.G., Nagle, H.T. and Black, R.D., 'An implantable radiation dosimeter for use in external beam radiation therapy.' Med Phys. 31(9):2658-71, 2004.

26. Varadhan, R., Miller, J., Garrity, B. and Weber, M., 'In vivo prostate IMRT dosimetry with MOSFET detectors using brass buildup caps.' J Appl Clin Med Phys, 28;7(4):22-32, 2006.

27. Morton, J.P., Bhat, M., Kovendy, A. and Williams, T., 'Evaluation of MOSFETs for entrance dose dosimetry for 6 and $10 \mathrm{MV}$ photons with a custom made build up cap.' Australas Phys Eng Sci Med, 30(2), 2007. 